\title{
PERSPECTIVE
}

\section{Gene therapy for inherited retinal degeneration}

\author{
R R Ali, M B Reichel, D M Hunt, S S Bhattacharya
}

Research into the molecular and genetic basis of disease is continually expanding and improving the prospects for rational treatments. Of these, gene therapy (here defined as the introduction of genetic material into human cells) may ultimately offer the greatest scope. ${ }^{1}$ This article provides a perspective on the potential for gene therapy for treating inherited retinal degenerations, along with an outline of progress and problems encountered to date. Of the inherited forms of retinal degeneration, retinitis pigmentosa (RP) is the best characterised (see $\operatorname{Bird}^{2}$ for review). Seven different non-syndromic RP genes have been identified to date, five of which ${ }^{3-7}$ are expressed exclusively in photoreceptor cells. However, photoreceptors and retinal pigment epithelial (RPE) cells are in close proximity and are interdependent. Defects in genes expressed in the RPE may also result in retinal degeneration. Delivery to these tissues of either normal copies of the defective genes or genes which enhance cell survival may arrest the degenerative process and thus preserve vision.

THE EYE AS TARGET ORGAN FOR GENE DELIVERY

The eye has a number of advantages as a target organ for gene delivery. It is easily accessible and the tissues may be examined in vivo by ophthalmoscopy. In addition, there are blood-retinal and blood-aqueous barriers which may concentrate vectors in the target area and reduce their spread out of the eye. The eye may be used for testing gene delivery to a wide range of tissues since it contains endothelium (cornea), epithelium (cornea, ciliary body, iris), muscle (ciliary body), and neurons (retina). It may also serve as a valuable model system to test gene therapy strategies for the brain, whose neurons are more difficult to target than those in the neuroretina.

SCOPE OF GENE THERAPY TO TREAT OCULAR DISORDERS

It is probable that gene therapy for certain ocular diseases will be realised sooner than others. Gene therapy strategies for cancers (for example, uveal melanoma), infections (for example, cytomegalovirus retinitis (CMV) retinitis), inflammation (for example, uveitis, proliferative vitreoretinopathy), and as an adjuvant to surgery (for example, to reduce scarring) probably only require short term gene expression which is not critically dependent upon precise regulation. However, gene therapy for inherited retinal degenerations, where there is a requirement for long term gene expression with appropriate regulation, will present considerable difficulties. Nevertheless, there are many monogenic disorders involving retinal degeneration and they are probably the most appropriate ocular disease candidates for gene therapy since they are at present untreatable - other genetic disorders such as familial cataracts or corneal dystrophies may be reasonably adequately treated by surgery/transplant. Although three main treatment strategies for retinal degenerations are currently under investigation in animals-replacement of photoreceptors ${ }^{8-12}$ or $\mathrm{RPE}^{13-15}$ by transplantation, rescue by intraocular injection of growth factors, ${ }^{16}{ }^{17}$ and restoration of function by gene delivery to the appropriate cells ${ }^{18}$ - the third strategy, gene therapy, potentially offers the most precise treatment. It aims in recessive disease to introduce a functional copy of the defective gene or in dominant diseases (other than in cases of haploinsufficiency) to specifically inactivate messages from the defective gene. Although there are many problems to be overcome before gene therapy becomes a viable treatment, the problems are fairly well defined, and each may be investigated systematically.

\section{In vivo gene delivery to ocular tissues}

Of fundamental importance to all gene therapy strategies is the delivery of genes to specific ocular tissues. Although in vitro, rather than in vivo, delivery is much easier to achieve and may utilise physical techniques (electroporation, microinjection, $\mathrm{CaPO}_{4}$ transfection, etc), most of the strategies under investigation for ocular gene therapy require an in vivo approach. The main challenge to date has therefore been to evaluate current vectors for efficient and safe delivery in vivo and how they might be improved.

THE MOUSE MODEL

The mouse has been used extensively as an animal model to evaluate gene therapy vectors. This is an appropriate choice since much is known about its biology, and there are many mouse models of ocular disease (comprising spontaneous mutants, transgenic animals, and experimentally induced conditions) which may be utilised for future experiments. It is important to deliver the vectors as close as possible to the target cells. Unfortunately, the small size of the mouse eye, combined with a relatively large lens, makes accurate delivery extremely difficult. Nevertheless, cells in and around the anterior chamber (corneal endothelium, iris pigment epithelium, ciliary body) may be targeted via intracameral injections, ganglion cells via intravitreal injection, and RPE and photoreceptor cells via subretinal injection (Fig 1).

EVALUATION OF VECTORS

Viruses are little more than highly efficient natural gene delivery systems and are thus obvious vehicles for gene delivery. They have evolved over millions of years to enter mammalian cells (sometimes extremely specifically via receptors) and to avoid endosomal degradation of their RNA or DNA message which is then targeted to the nucleus. The mechanisms by which viruses achieve this have yet to be fully understood. Modified recombinant viruses, which are also replication deficient as a result of deletions in essential viral genes, are currently the most widely used vectors for in vivo gene transfer. ${ }^{19}{ }^{20}$ Each viral vector system has its advantages and disadvantages and those that have been used to date for ocular gene delivery are reviewed below. 


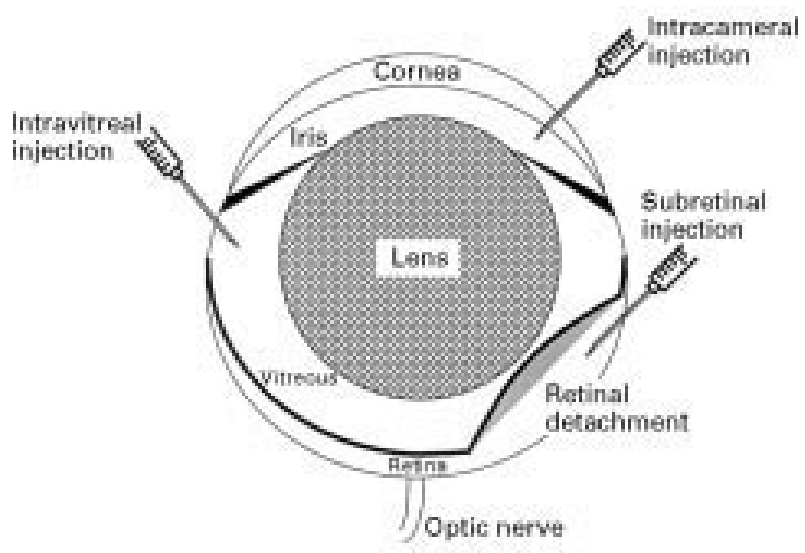

Figure 1 Schematic of the mouse eye. Note that the lens is proportionally much larger in mice than in humans. The routes of intraocular injections are indicated.

\section{Retroviruses}

Retroviruses are ssRNA viruses which require cell division for transfection; recombinant retroviruses are therefore limited in their use for in vivo gene transfer as ocular tissues are either terminally differentiated, or divide very slowly (for example, RPE). Anterior chamber and posterior chamber injections of a disabled (replication deficient) recombinant murine leukaemia virus (rMLV) containing a lac $\mathrm{Z}$ reporter gene fail to produce transduced cells. This property, however, has been utilised to target dividing cells in brain tumours ${ }^{21}$ (a strategy which might be also be utilised to target ocular tumours) and more recently to target dividing cells in a rabbit model of proliferative vitreoretinopathy. ${ }^{22}$ Other potential targets for retroviral mediated gene therapy might be vascular proliferation arising from choroidal or retinal vessels.

\section{Herpes simplex virus (type 1)}

Herpes simplex virus (HSV) is a large dsDNA virus. Two types of HSV vector, reviewed by Coffin and Latchman, ${ }^{23}$ are used for gene transfer-disabled viruses and amplicons (the latter consist of concatamers of plasmids, containing an HSV origin of replication, packaging signal and transgene, packaged into HSV virions by disabled helper virus). We have demonstrated, using a variety of replication deficient HSV vectors containing a lacZ reporter, that this is an effective method of transducing all cell types in the eye, including photoreceptors. The virus has a number of intrinsic properties which make it useful: the potential to accommodate large genes (perhaps up to $30 \mathrm{~kb}$ if all nonessential regions are deleted); the possibility of production at high titres, up to $10^{10} \mathrm{pfu}$ (plaque forming units) (which is useful for ocular transfer where there is a volume restriction) and the ability to remain hidden from the immune system allowing lifelong infections (because it shuts down most viral gene expression during latency). Its natural tropism for peripheral neurons make it of considerable interest for gene delivery to photoreceptor cells. ${ }^{24}$

However, HSV vectors currently suffer from a number of drawbacks. With most of the currently available vectors, in vivo transduction has been limited to a matter of days. We have investigated several different $\mathrm{rHSV}$ vectors and have observed reporter gene expression for up to only 4 days, even in immunodeficient nude animals (unpublished data). The limited duration of reporter gene expression could be due to toxicity of the virus, but is more likely to be the result of the virus entering latency and switching off most gene expression. Finally, wild type HSV, on which recombinant vectors are based, is a highly pathogenic virus. Replication competent HSV, if injected subretinally,

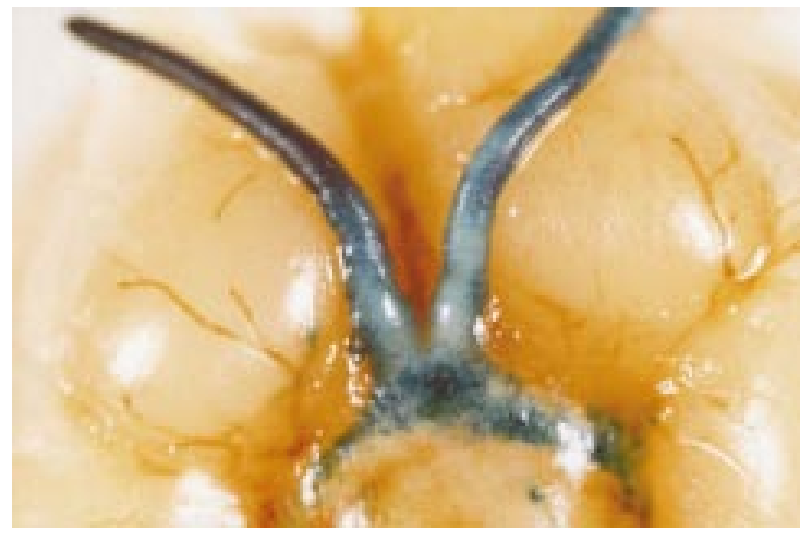

Figure 2 Blue $X$-gal staining indicates lac $Z$ activity in the optic nerve and optic chiasma of a BALB/c mouse 3 days after subretinal injection of $2 \mu \mathrm{l}$ suspension of replication competent $H S V$ virus, BE $8\left(5 \times 10^{9} \mathrm{pfu} / \mathrm{ml}\right)$ in which the lacZ, driven by a CMV promoter, has been inserted into the non-essential Us5 gene.

will spread along the optic nerve and into the brain where it may cause a fatal encephalopathy (see Fig 2). Thus, maximum consideration must be given to ensuring that rHSV vectors are safe for clinical use. The possibility of rHSV reactivating latent wild type virus in the recipient must be excluded.

HSV is a complex virus whose biology is still not fully understood, particularly with regard to the mechanism of latency and reactivation. Central to the process of viral inactivation is the latency associated transcript (LAT) which is the only gene that is active during latency. In order to circumvent the switching off of transgene expression during viral inactivation, a number of groups have produced rHSV vectors containing reporter genes driven by the LAT promoter. Lokensgard et $a l^{25}$ have been able to demonstrate reporter gene expression in mouse dorsal root ganglion cells for up to 42 days. It would be interesting to determine whether similar constructs are capable of driving long term expression in the neuroretina.

\section{Adenovirus}

Adenovirus (AV) is a small dsDNA virus. Of all vectors, replication deficient recombinant $\mathrm{AV}$ vectors have been the most extensively studied for in vivo gene transfer to the eye. ${ }^{26-33}$ They have a number of advantages: wild type AV is

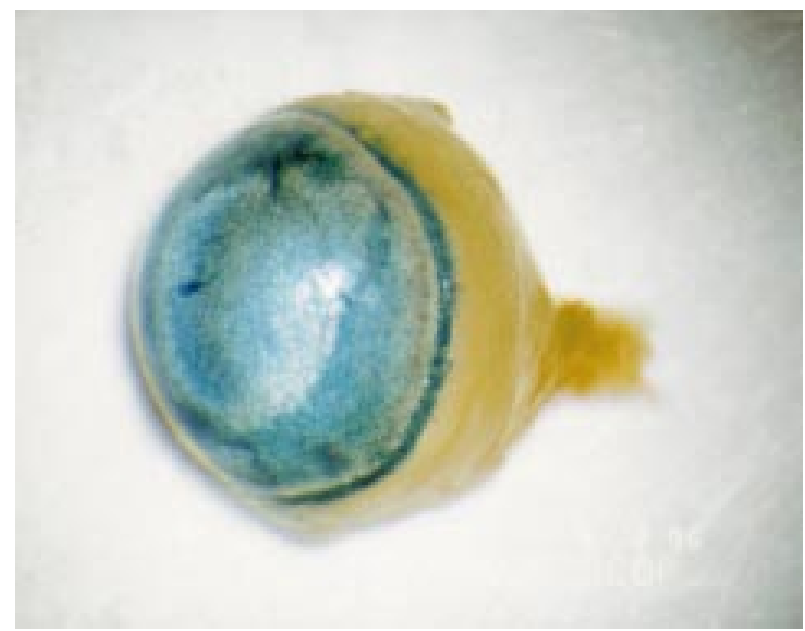

Figure 3 Blue $X$-gal staining in the anterior chamber of adult $B A L B / c$ mouse after intracameral injection of $2 \mu \mathrm{l}$ of adenovirus carrying a lacZ gene with nuclear localisation signal driven by a CMV promoter (AV.CMV.LacZnuc) at a titre of $1 \times 10^{9} \mathrm{pfu} / \mathrm{ml}$. LacZ activity can be observed throughout the anterior segment including corneal endothelium, iris, and trabecular meshwork. 

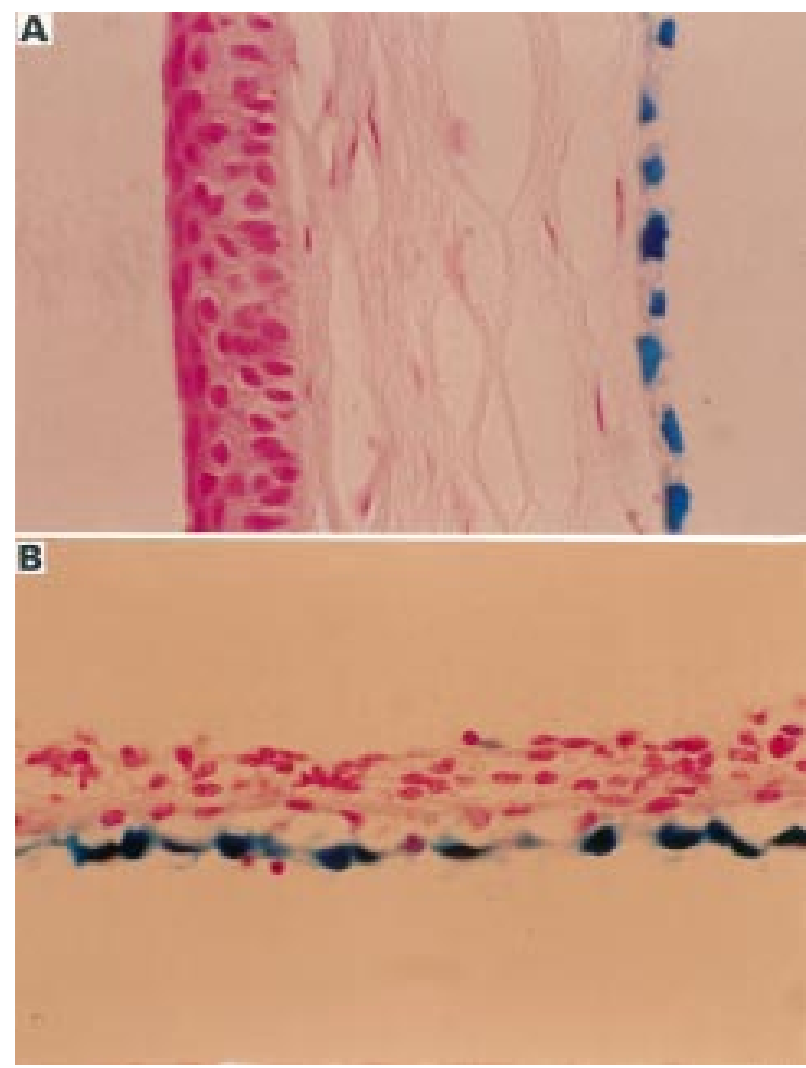

Figure 4 Transduced corneal endothelium $(A)$ and iris pigment epithelium (B) in adult $B A L B / c$ mouse after intracameral injection of $2 \mu \mathrm{l}$ of AV.CMV.LacZnuc $\left(1 \times 10^{9} \mathrm{pfu} / \mathrm{ml}\right)$. A 5 um paraffin section counterstained with nuclear fast red $(\times 45)$.

not highly pathogenic, the vectors may be purified to high titres $\left(10^{12} \mathrm{pfu} / \mathrm{ml}\right)$, and the virus is able to infect a wide range of ocular cell types.

Anterior chamber injections of $\mathrm{AV}$ vectors carrying a lacZ transgene driven by a viral promoter results in the widespread transduction of cells in the anterior segment in mice $^{31}$ (Fig 3) and rabbits. ${ }^{32}{ }^{33}$ Corneal endothelium and iris pigment epithelium are readily transduced ${ }^{28}{ }^{29}$ 31-33 $^{\text {(Fig }}$ $4 \mathrm{~A}$ and $4 \mathrm{~B}$ ). In our experience, the ciliary body, Schlemm's canal, and trabecular meshwork are also often positive. Although this has been reported by Budenz et al, ${ }^{31}$ others have not reported transduction of all three structures. This may reflect differences in injection technique or the number of viral particles. The virus does not penetrate the corneal stroma following an intracameral injection and thus does not transduce corneal epithelium. The lens epithelium appears to be resistant to transduction unless the capsule is damaged by the injection. ${ }^{30}{ }^{33}$ This is more likely to occur during an anterior chamber injection than during an intravitreal injection. Intravitreal injections may result in a similar pattern of transduction, although ganglion cells may now be transduced (Bennett et al reported this in 13\% of their intravitreal injections ${ }^{27}$ ). Again, variation in the literature may reflect differences in titres and technique. Mashhour et $a l^{29}$ are alone in reporting transduction of all layers of the retina after intravitreal injection. However, from our own observations this is probably due to an injection technique which disrupts the retina.

After subretinal injection, highly efficient transduction of RPE is observed but there is very poor transduction of photoreceptor cells ${ }^{27} 28$ (Fig 5). These cells may, however, be more efficiently transduced if they are in the process of development (neonatal mice at day 5) or in the process of degeneration (2.5-month-old $r d s$ mice).$^{28}$ In both cases, photoreceptors may be more accessible to virus. It is

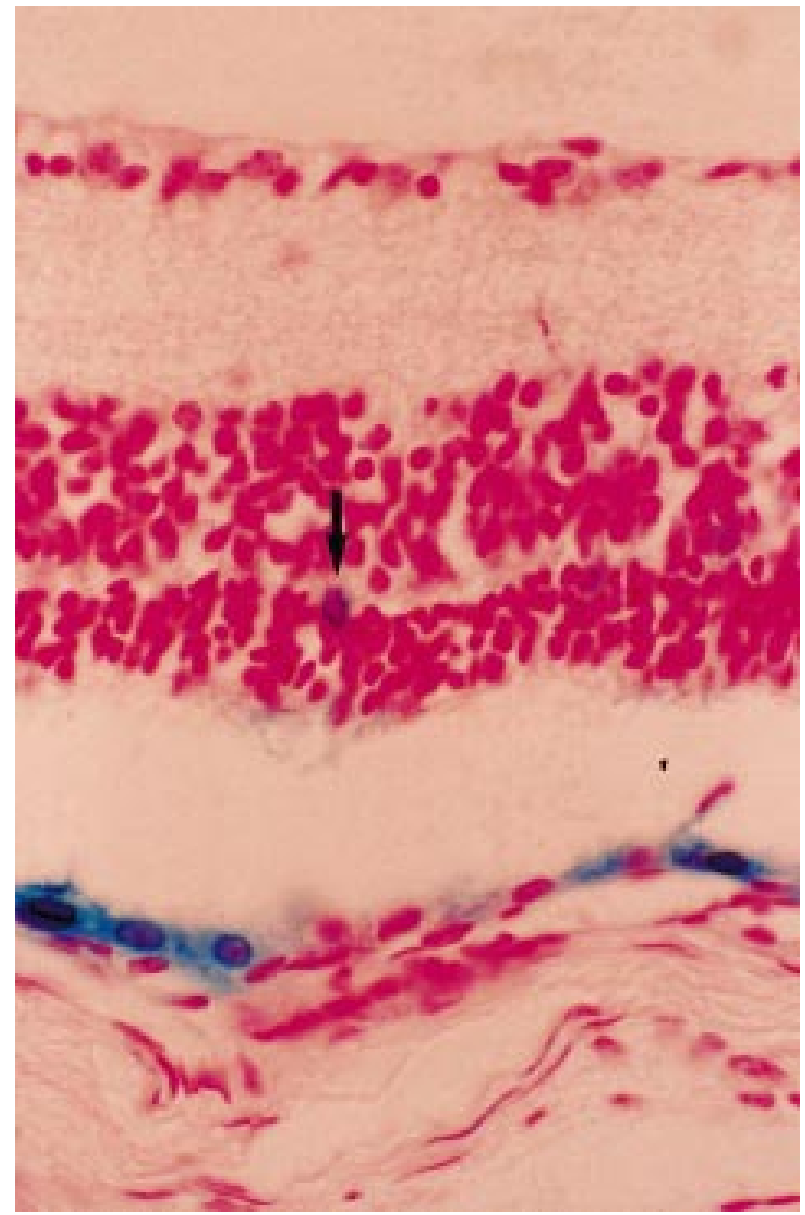

Figure 5 Transduced retinal pigment epithelium and occasional positive photoreceptor cell (arrow) in adult BALB/c mouse 2 weeks after subretinal injection of $2 \mu \mathrm{l}$ of AV.CMV.LacZnuc $\left(1 \times 10^{9} \mathrm{pfu} / \mathrm{ml}\right)$. A 5 um paraffin section counterstained with nuclear fast red $(\times 66)$.

unlikely that the first observation is of clinical relevance for treating inherited retinal degeneration since human photoreceptors are fully developed at birth. However, the second is worth noting since the first clinical trials would probably take place in older patients, where a higher transduction efficiency may offset problems associated with the treatment of degenerate retinas. Higher titres of AV result in much better transduction of photoreceptors. Bennett et al reported that in adult mice transduction of the neuroretina required the injection of at least $1 \times 10^{7} \mathrm{pfu}^{27}$ However, this must be weighed against the possibility of direct toxicity to the cells, especially to adjacent RPE cells which take up the virus very efficiently. One week after subretinal injection, disruption of the retina and damage to photoreceptor outer segments can be observed, ${ }^{27}{ }^{28}$ but by 6 weeks this is resolved. ${ }^{28}$ Cytopathic changes have been observed after intraocular injection of $10^{8} \mathrm{pfu}$ in mice. ${ }^{28} \mathrm{At}$ 8 weeks post-injection, $\mathrm{Li}$ et al observed that there were a reduced number of photoreceptors in some sections.

In our experience, using BALB/c mice, ocular AV mediated reporter gene expression usually lasts no more than 3 weeks (Ali, unpublished results). We have also demonstrated that an immune response limits the duration of expression in both anterior and posterior segments and is directed primarily at the vector (manuscript in preparation). In general, inflammatory cells have not been noted in post-injected retinas. However, they may be present in the vitreous which is usually removed during processing. Borras et $a l^{33}$ have observed infiltrating cells in rabbits 2 days after anterior chamber injection of $10^{9} \mathrm{pfu}$. It appears 
therefore that 'immune privilege' associated particularly with transplants into the anterior chamber (but more recently also to the subretinal space ${ }^{35}$ ) does not apply to cells infected with virus by intraocular injection. This is perhaps not surprising since virus injected into the anterior segment drains out into the venous blood stream and injection of virus into the posterior segment disrupts the blood-retinal barrier. Li et $a l,{ }^{28}$ however, have observed scattered reporter gene expression 6 weeks after injecting neonatal CB-17 mice (which are almost genetically identical to BALB/c), presumably by circumventing the developing immune system. Although there have been reports of much longer gene expression after intraocular injection of adult mice (for 13 weeks in two CD-1 mice ${ }^{27}$ ) strain differences may account for some of the discrepancies. We have shown, for instance, that lac $Z$ expression is maintained for around 1 week longer in MF1 mice than in $\mathrm{BALB} / \mathrm{c}$ mice. The immunogenicity of AV vectors may be reduced in the future as new vectors are being developed which contain fewer viral genes. This may, however, generate a new problem of efficient in vitro production of recombinant virus. Alternatively it may be possible to tolerise animals to the vector.

\section{Adeno-associated virus}

Adeno-associated viral (AAV) vectors have generated considerable interest recently. They are potentially very attractive since wild type AAV, a tiny ssDNA parvovirus, is not associated with any pathology in humans $(40 \%$ of the population is seropositive for AAV without ill effect). In addition, recombinant AAV vectors are deleted for all virally encoded proteins, therefore reducing their immunogenicity. Furthermore, rAAV is capable of transducing non-dividing neuronal cells. Although the wild type virus integrates site specifically into chromosome 19, rAAV lacks the ability to do this and probably remains in the nucleus as an episome. We have now demonstrated that, after subretinal injection, rAAV is 2000 -fold more efficient at transducing photoreceptor cells than a rAV vector containing a similar reporter construct ${ }^{34}$ (Fig 6). As with AV, the RPE is very efficiently transduced, and we have also observed transduced cells in the bipolar and ganglion cell layers. Expression of the reporter gene in immunodeficient mice was detected up to 1 month after injection. ${ }^{34}$ Because of its small size, the virus may be able to penetrate the layers of the retina. After subretinal injection of mice we have observed transduced ganglion and bipolar cells and Zolotukhin et al have observed transduced RPE cells in the guinea pig after intravitreal injection of a rAAV carrying a green fluorescent protein (GFP) reporter. ${ }^{36}$

AAV vectors currently have a number of limitations: the virus is very difficult to prepare to high titres and without contamination with helper AV. The maximum size of insert that the vector is able to accommodate is only $4.7 \mathrm{~kb}$. In addition, it now appears that transduction by AAV may require coinfection of cells with (contaminating) wild type AV which may facilitate the conversion of ssDNA to the ds form. ${ }^{37}{ }^{38}$ These problems will need to be addressed before AAV vectors can be considered as suitable vectors for gene delivery in humans.

\section{Future vector development}

The DNA viruses which have been investigated to date (HSV, AV, and AAV) are all efficient at transducing non-neuronal cells, in particular the RPE, which probably phagocytoses the virus. A major challenge for ocular gene therapy is to further improve the efficiency of transduction of neuronal cells and in particular photoreceptor cells, and to reduce the immune responses in order to achieve long term gene expression. Each of the viral vectors have poten-

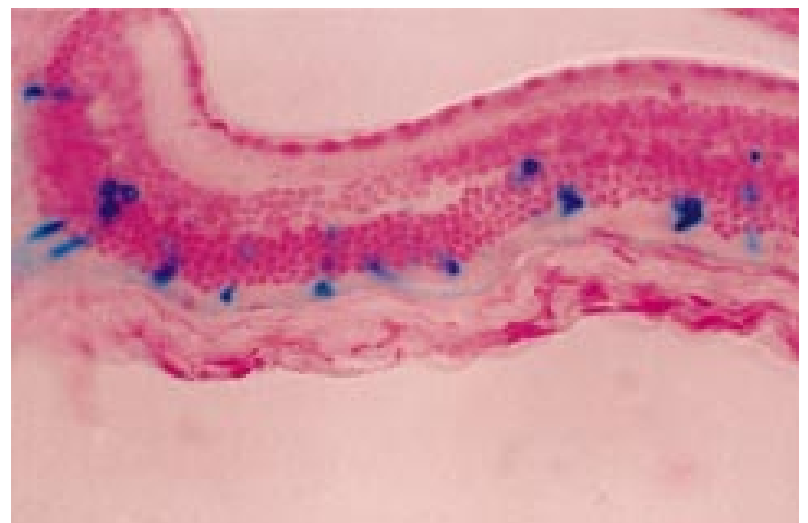

Figure 6 Transduced photoreceptor cells in adult nude mouse 1 month after subretinal injection of $2 \mu \mathrm{l}$ of AAV.CMV.LacZ $\left(1 \times 10^{7} \mathrm{IU} / \mathrm{ml}\right)$. All the stained outer segments can be related to stained photoreceptor nuclei which is consistent with transduction of photoreceptor cells and subsequent transport of LacZ into the outer segments. A 5 um paraffin section counterstained with nuclear fast red $(\times 25)$.

tial advantages and disadvantages, but in general it appears that $\mathrm{AV}$ vectors may be most suitable for transducing nonneuronal ocular cells, whereas AAV appears to be a promising vector system for gene delivery to photoreceptor cells-provided the requirement for wild type AV can be overcome. HSV vectors probably require the most development.

Although a number of vectors have already been used for ocular gene delivery, it will be essential to evaluate new vector systems as they are developed. For instance, the possibilities of utilising modified lentiviruses for gene transfer to photoreceptors has recently been raised with the demonstration of reporter gene delivery to neuronal cells using an HIV vector. ${ }^{39}$ The potential advantage of using such retroviruses is the possibility of stable transduction. Alternative vector systems which utilise a viral packaging system, but contain minimal viral DNA (such as HSV amplicons and the polyoma system) have not yet been investigated with respect to their potential use in the eye. Although non-viral gene delivery systems such as liposomes have so far proved to be generally very inefficient in vivo (also in the eye, unpublished data), they have the advantages of low toxicity and immunogenicity and with further development may prove useful. They may also be used to improve the transduction efficiency of viral vectors. $^{40}$

\section{Experimental gene therapy strategies using mouse models of retinal degeneration}

An essential requirement for the development of gene therapy is the availability of suitable well characterised animal models. Since mice are relatively inexpensive to maintain, well characterised genetically, and are used for transgenic manipulations most animal models are murine (and given the rapid progress in mouse genetics this will continue to be so in the future). Various gene therapy strategies can be employed to treat disease in these models. In general, ablation of specific cells is often the goal for gene therapy for experimentally induced non-genetic diseases such as uveal melanoma and proliferative vitreoretinopathy (and is outside the scope of this review), whereas restoration of function is the goal for gene therapy of genetic disorders.

GENE DELIVERY TO PHOTORECEPTORS

Recessive disorders, caused by loss of function, and those dominant diseases caused by haploinsufficiency, where $50 \%$ of the gene product is inadequate for normal 
function, are more straightforward to treat by gene therapy than dominant disorders in which there is a gain of function. The remainder of this section concentrates on the two extensively characterised mouse strains, $r d$ (retinal degeneration) and $r d s$ (retinal degeneration slow), which respectively provide recessive and dominant haploinsufficiency models of RP. In each case the photoreceptor cells degenerate and are lost through apoptosis. ${ }^{41}$

The defect in the $r d$ mouse is a recessive null mutation in the bPDE gene (which encodes the $\beta$ subunit of rod phosphodiesterase) and leads to a rapid and severe degeneration in homozygous mice. ${ }^{42}$ Photoreceptors are lost within 1 week of birth, with $50 \%$ loss by 2 weeks (heterozygous mice are indistinguishable from wild type). Bennett et al have slowed the degeneration in the $r d$ mouse by subretinal injection in 5-day-old pups of a rAV vector carrying a bPDE gene driven by a viral promoter. ${ }^{18}$ Three weeks after injection, they were able to demonstrate areas of the retina with three or four layers of photoreceptor cells (compared with one layer in the untreated $r d$ mouse and eight to nine layers in a normal adult mouse). By 7 weeks there was little difference between treated and untreated mice. It is not clear what proportion of photoreceptors had been transduced but it seems unlikely that the additional layers of outer nuclei consist only of transduced cells. It is possible that this phenotype resulted from the transduction of scattered photoreceptors as might be expected from previous studies, ${ }^{27}{ }^{28}$ with rescue of surrounding cells. Alternatively, rescue may have been effected primarily by transduction of RPE cells with secretion of the $\beta P D E$ gene product and uptake by the photoreceptors. These possibilities could be readily distinguished by immunohistochemical staining for $\beta \mathrm{PDE}$ and by repeating the experiment using a rAV carrying the $\beta P D E$ gene driven by a photoreceptor specific promoter. The defect in the $r d s$ mouse is a null mutation in the peripherin/rds gene which encodes a structural protein required for outer segment stability. ${ }^{43}$ These mice were first characterised by Sanyal et al. ${ }^{44}$ Mice homozygous for the $r d s$ mutation lack outer segments and 3 weeks after birth begin to lose photoreceptor cells. By 2 months, the outer nuclear layer is reduced to approximately half its thickness. Mice heterozygous for the mutation are characterised by abnormal outer segments and a much slower loss of photoreceptor cells. ${ }^{45}$ The defect is thus more accurately described as a semidominant mutation since the heterozygote has an intermediate phenotype between wild type and homozygous mice and is due to haploinsufficiency. The heterozygous $r d s$ mouse will prove particularly useful for gene delivery to photoreceptor cells since the pathology is rather mild and the rate of degeneration is relatively slow, making it a good model for late onset autosomal dominant RP. Once photoreceptor cells have degenerated beyond a certain point, gene delivery is unlikely to be beneficial. Since the peripherin/rds protein is a structural protein, overexpression of the gene in photoreceptor cells may be deleterious: the photoreceptors of transgenic mice carrying multiple copies of a normal rhodopsin transgene eventually degenerate. ${ }^{46}$ Therefore, long term correction of the defect in this mouse model will probably require precise control of the level of expression of the introduced gene-with appropriate promoter and multiplicity of infection.

There are a number of transgenic mouse models of dominant RP, in which photoreceptor degeneration results from dominant mutations in either a rhodop $\sin ^{46-48}$ or peripherin/rds transgene ( $G$ Travis, personal communication). One strategy to slow degeneration in these mice might be to overexpress the normal gene, thereby competing out abnormal protein with normal. However, it is unclear what ratio of proteins might be required and to what extent overexpression of the normal protein would lead in itself to disease. Prevention of the degeneration will probably require specific inactivation of the abnormal message. In the case of dominant rhodopsin mutations this should be sufficient to prevent disease since there would be haplosufficiency (individuals who are heterozygous for a rhodopsin null mutation are unaffected ${ }^{49}$ ). However, in the case of dominant peripherin mutations, where there is a gain of function, inactivation of the abnormal message may not be entirely sufficient to prevent disease since this may then lead to haploinsufficiency. The potential of ribozymes has been demonstrated in vitro and that of antisense DNA in cell culture. Recent evidence has supported the use of antisense constructs in vivo..$^{50-52}$

Initially, it is simpler to assess the effects of gene transfer on correcting abnormal ultrastructure and histology, than to assess its effects on visual transduction. Since Huang et al have demonstrated, with aggregation chimeras between normal and transgenic mice expressing a mutant rhodopsin gene, that normal photoreceptors degenerate if surrounded by abnormal photoreceptors ${ }^{48}$ it may not be sufficient to rescue a small proportion of cells. Because photoreceptor cells are so difficult to target, there is still much work left to be done. Our best efforts to date have resulted in transduction of less than $1 \%$ of the total photoreceptor cell population.

GENE DELIVERY TO THE RPE

Transduction of the RPE is much more efficient than that of neuroretina, probably reflecting the phagocytic property of this cell type. Primary biochemical defects in the RPE may lead to photoreceptor degeneration. For instance, the retinal dystrophy $(r d y)$ rat (also known as the Royal College of Surgeons' rat) has a single, as yet unidentified, gene defect of the RPE which results in retinal degeneration. $^{53}$ It is tempting to speculate that a proportion of the uncloned RP genes may turn out to have a function in the RPE. These diseases would thus be prime candidates for gene therapy (and indeed the candidate gene for RP3, RPGR, may prove to be such a gene ${ }^{54}$ ). Age related macular degeneration (AMD), which has both environmental as well as genetic components, is also thought to result partly from an RPE abnormality (accumulation of lipofuscin). This widespread condition is also a potential candidate for gene therapy. Overexpression in the RPE of enzymes which degrade lipofuscin deposits may ameliorate the condition. Although an accurate model of AMD does not exist, the mnd mouse, a model for Battens' disease, exhibits a build up of lipofuscin in the $\mathrm{RPE}^{55}$ and might be useful for testing such therapies.

An alternative strategy to treat retinal degeneration might involve the use of growth factors to promote photoreceptor survival. This approach, using either direct injection or recombinant viruses to deliver brain derived neurotrophic factor (BDNF) and ciliary neurotrophic factor (CNTF) to the central nervous system, has had some success in reducing the damage seen in several neurodegenerative mouse models. ${ }^{56}$ Although single intravitreal injections of either BDNF or CNTF into $r d$ and $r d s$ mice have not slowed the degeneration, it is possible that long term treatment with these factors may ameliorate the condition. Given the efficiency with which the RPE and corneal endothelium may be transduced, this might be achieved using either rAV or rAAV to deliver the various growth factor genes to these tissues.

A number of neurodegenerative diseases have an associated retinal degeneration. One such disease is mucopolysaccharidosis VII, a recessive lysosomal storage disease resulting from a deficiency of $\beta$ glucuronidase, that leads to lysosomal accumulation of glycosaminoglycans in the RPE 
and subsequent photoreceptor degeneration. $\mathrm{Li}$ and Davidson have reported the phenotypic correction of the RPE defect in the gus $^{m p s}$ murine model of mucopolysaccharidosis VII using a rAV vector. ${ }^{30}$ However, it is not yet clear whether this resulted from replacing the missing gene product since, in the absence of a suitable control (for example, rAV carrying lac $Z$ ), it is also possible that the transduced RPE cells had been ablated by a cytotoxic immune response to the vector, and then been replaced by new RPE cells. These new cells may then not have had sufficient time for the lysosomal accumulation of glycosaminoglycans.

\section{Conclusion}

The potential for gene therapy in the treatment of ocular disease has only recently been explored. Although in vivo gene delivery of reporter genes, using a variety of viral vectors, has indicated the feasibility of ocular gene therapy, considerable improvements with respect to efficiency of the currently available vector systems is required. In particular, the efficiency of transduction of photoreceptor cells must be improved and the duration of expression increased. The problem of immune responses to exogenous proteins (particularly derived from the vector) should be addressed since, as in other organs, they will limit the duration of expression of transgenes in the eye. Substantial progress in the treatment of disease in animal models must be demonstrated, and concerns regarding the safety of vectors satisfied, before clinical trials can be contemplated. However, past experience justifies a cautious optimism that considerable improvements to this emerging technology will be achieved in the next decade.

R R ALI

M B REICHEL D M HUNT

\section{S S BHATTACHARYA}

Department of Molecular Genetics, Institute of Ophthalmology, UCL, Bath Street, London EC1V

Correspondence to: Robin Ali.

1 Culver KW. Measuring success in clinical gene therapy research. Mol Med Today 1996;2:234-6.

2 Bird AC. Retinal photoreceptor dystrophies. Am f Ophthalmol 1995;119: 543-62

3 Dryja TP, Finn JT, Peng Y-W, McGee TL, Berson EL, Yau KW. Mutations in the gene encoding the $\alpha$ subunit of the rod cGMP-gated channel in autosomal recessive retinitis pigmentosa. Proc Natl Acad Sci USA 1995;92: $10177-81$.

4 Bascom RA, Liu L, Heckenlively JR, Stone EM, McInnes RR. Mutation analysis of the ROM1 gene in retinitis pigmentosa. Hum Mol Genet 1995;4: 1895-902.

5 McLaughlin ME, Sandberg MA, Berson EL, Dryja TP. Recessive mutations in the gene encoding the $\beta$-subunit of rod phosphodiesterase in patients with retinitis pigmentosa. Nature Genet 1993;4:130-4

6 Farrar GJ, Kenna P, Jordan SA, Kumar-Singh R, Humphries MM, Sharp $\mathrm{EM}$, et al. A three base-pair deletion in the peripherin-RDS gene in one form of retinitis pigmentosa. Nature 1991;354:478-80.

7 Dryja, TP, McGee TL, Reichel E, Hahn LB, Cowley GS, Yandell DW, et al. A point mutation of rhodopsin gene in one form of retinitis pigmentosa. Nature 1990;343:364-6.

8 Gouras P, Du J, Kjeldbye H, Yamamoto S, Zack DJ. Long-term photoreceptor transplants in dystrophic and normal mouse retina. Invest Ophthalmol tor transplants in dystrop

9 Gouras P, Du J, Kjeldbye H, Yamamoto S, Zack DJ. Reconstruction of degenerate $r d$ mouse retina by transplantation of transgenic photoreceptors. Invest Ophthalmol Vis Sci 1992;33:2579-86.

10 Silverman MS, Hughes SE, Valentino TL, Liu Y. Photoreceptor transplantation: anatomic, electrophysiologic, and behavioral evidence for the functional reconstruction of retinas lacking photoreceptors. Exp Neurol 1992;115:87-94.

11 Aramant RB, Seiler MJ. Fiber and synaptic connections between embryonic retinal transplants and host retina. Exp Neurol 1995;133:244-55.

12 Zucker CL, Ehinger B, Seiler M, Aramant RB, Adolph AR. Ultrastructural circuitry in retinal cell transplants to rat retina. $\mathcal{F}$ Neural Transplant Plast 1994;5:17-29.

13 Little CW, Castillo B, DiLoreto DA, Cox C, Wyatt J, del Cerro C, et al. Transplantation of human fetal retinal pigment epithelium rescues photoreceptor cells from degeneration in the Royal College of Surgeons rat photoreceptor cells from degeneration in the Roy
retina. Invest Ophthalmol Vis Sci 1996;37:204-11.

14 Sheng Y, Gouras P, Cao H, Berglin L, Kjeldbye H, Lopez R, et al. Patch transplants of human fetal retinal pigment epithelium in rabbit and monkey retina. Invest Ophthalmol Vis Sci 1995;36:381-90.
15 Yamamoto S, Du J, Gouras P, Kjeldbye H. Retinal pigment epithelial transplants and retinal function in RCS rats. Invest Ophthalmol Vis Sci 1993;34: $3068-75$.

16 Unoki K, LaVail MM. Protection of the rat retina from ischemic injury by brain-derived neurotrophic factor, ciliary neurotrophic factor, and basic fibroblast growth factor. Invest Ophthalmol Vis Sci 1994;35:907-15.

17 LaVail MM, Unoki K, Yasumura D, Matthes MT, Yancopoulos GD, Steinberg RH. Multiple growth factors, cytokines, and neurotrophins rescue photoreceptors from the damaging effects of constant light. Proc Natl Acad Sci USA 1992;89:11249-53.

18 Bennett J, Tanabe T, Sun D, Zeng Y, Kjeldbye H, Gouras P, Maguire AM. Photoreceptor cell rescue in retinal degeneration $(r d)$ mice by in vivo gene therapy. Nature Med 1996;2:649-54.

19 Gunzburg WH, Salmons B. Virus vector design in gene therapy. Mol Med Today 1995;1:411-17.

20 Ali M, Lemoine NR, Ring CJA. The use of DNA viruses for gene therapy. Gene Therapy 1994;1:367-84.

21 Ram Z, Culver KW, Walbridge S, Blaese RM, Oldfield EH. In situ retroviral mediated gene transfer for the treatment of brain tumours in rats. Cancer Res 1993;53:83-8.

22 Kimura H, Sakamoto T, Cardillo JA, Spee C, Hinton DR, Gordon EM, et al. Retrovirus-mediated suicide gene transduction in the vitreous cavity of the eye: feasibility in the prevention of proliferative vitreoretinopathy. Human Gene Therapy 1996;7:799-808.

23 Coffin RS, Latchman DS. Herpes simplex virus-based vectors. In: Latchman DS, ed. Genetic manipulation of the nervous system. London: Academic Press, 1996:99-111.

24 Pepose JS, Leib DA. Herpes simplex viral vectors for therapeutic gene delivery to ocular tissues - recent breakthroughs in the molecular genetics of ocular diseases. Invest Ophthalmol Vis Sci 1994;35:2662-6.

25 Lokensgard JR, Bloom DC, Dobson AT, Feldman LT, Stevens JG. Long-term promoter activity during herpes simplex virus latency. $\mathcal{F}$ Virol 1994;68:7148-58.

26 Jomary C, Piper TA, Dickson G, Couture LA, Smith AE, Neal MJ, et al. Adeno-virus mediated gene transfer to murine retinal cells in vitro and in vivo. FEBS Lett 1994;347:117-22.

27 Bennett J, Wilson J, Sun D, Forbes B, Maguire A. Adenovirus vector-mediated in vivo gene transfer into adult murine retina. Invest $O p h$ thalmol Vis Sci 1994:35:2535-42.

$28 \mathrm{Li} \mathrm{T}$, Adamian M, Roof DJ, Berson EL, Dryja TP, Roessler BJ, et al. In vivo transfer of a reporter gene to the retina mediated by an adenoviral vector. Invest Ophthalmol Vis Sci 1994;35:2543-9.

29 Mashhour B, Couton D, Perricaudet M, Briand P. In vivo adenovirus mediated gene transfer into ocular tissues. Gene Therapy 1994;1:112-26.

$30 \mathrm{Li} \mathrm{T}$, Davidson BL. Phenotype correction in retinal pigment epithelium in murine mucopolysaccharidosis VII by adenovirus-mediated gene transfer. Proc Natl Acad Sci USA 1995;92:7700-4.

31 Budenz DL, Bennett J, Alonso L, Maguire A. In vivo gene transfer into murine corneal endothelial and trabecular meshwork cells. Invest Ophthalmol Vis Sci 1995;36:2211-5.

32 Abraham NG, da Silva J-L, Lavrovsky Y, Stoltz RA, Kappas A, Dunn MW, et al. Adenovirus-mediated heme oxygenase-1 gene transfer into rabbit et al. Adenovirus-mediated heme oxygenase-1 gene transfer

33 Borras T, Tamm ER, Zigler JSJ. Ocular adenovirus gene transfer varies in efficiency and inflammatory response. Invest Ophthalmol Vis Sci 1996;37: efficiency

34 Ali RR, Reichel MB, Thrasher AJ, Levinsky RJ, Kinnon C, Kanuga N, et al. Gene transfer into the mouse retina mediated by an adeno-associated viral vector. Human Mol Genet 1996;5:591-4.

35 Jiang LQ, Streilein JW. Subretinal space and vitreous cavity as immunologically privileged sites for retinal allografts. Invest Ophthalmol Vis Sci 1993;34:3347-54.

36 Zolotukhin S, Potter M, Hauswirth WW, Guy J, Muzyczka N. A 'humanized' green fluorescent protein cDNA adapted for high-level expression in mammalian cells. F Virol 1996;70:4646-54.

37 Ferrari F, Samulski T, Shenk T, Samulski RJ. Second-strand synthesis is a rate-limiting step for efficient transduction by recombinant adenorate-limiting step for efficient transduction by

38 Fisher K, Guang-Ping G, Weitzman MD, DeMatteo R, Burda JF, Wilson JM. Transduction with recombinant adeno-associated virus for gene
therapy is limited by leading-strand synthesis. F Virol 1996;70:520-32.

39 Naldini L, Blomer U, Gallay P, Ory D, Mulligan R, Gage FH, et al. In vivo gene delivery and stable transduction of nondividing cells by a lentiviral vector. Science 1996;272:263-7.

40 Hodgson CP, Solaiman R. Virosomes: cationic liposomes enhance retroviral transduction. Nature Biotec 1996;14:339-42.

41 Chang G-Q, Hao Y, Wong F. Apoptosis: final common pathway of photoreceptor death in $r d, r d s$, and rhodopsin mutant mice. Neuron 1993;11:595605.

42 Farber DB, Flannery JG, Bowes-Rickman C. The rd mouse story: seventy years of research on an animal model of inherited retinal degeneration. Prog Ret Eye Res 1994;13:31-64.

43 Molday RS. Peripherin/rds and rom-1: molecular properties and role in photoreceptor cell degeneration. Prog Ret Eye Res 1994;13:271-99.

44 Sanyal S, De Ruiter D, Hawkins RK. Development and degeneration of retina in rds mutant mice. 7 Comp Neurol 1980;194:193-207.

45 Hawkins RK, Jansen HG, Sanyal S. Development and degeneration of retina in rds mutant mice: photoreceptor abnormalities in the heterozygotes. Exp Eye Res 1985;41:701-20

46 Olsson JE, Gordon JW, Pawlyk BS, Roof D, Hayes A, Molday RS, et al. Transgenic mice with a rhodopsin mutation (Pro23His): a mouse model of autosomal dominant retinitis pigmentosa. Neuron 1992;9:815-30

47 Naash MI, Hollyfield JG, al Ubaidi MR, Baehr W. Simulation of human autosomal dominant retinitis pigmentosa in transgenic mice expressing a mutated murine opsin gene. Proc Natl Acad Sci USA 1993;90:5499-503.

48 Huang PC, Gaitan AC, Hao Y, Petters RM, Wong F. Cellular interactions implicated in the mechanism of photoreceptor degeneration in transgenic mice expressing a mutant rhodopsin gene. Proc Natl Acad Sci USA 1993;90:8484-8

49 Rosenfeld PJ, Cowly GS, McGee TL, Sandberg MA, Berson EL, Dryja TP. A null mutation in the rhodopsin gene causes rod photoreceptor dysfunction null mutation in the rhodopsin gene causes rod photoreceptor dysfunction

50 Ishihara H, Tashiro F, Ikuta K, Asano T, Katagiri H, Inukai K, et al. Inhibition of pancreatic beta-cell glucokinase by antisense RNA expression in 
transgenic mice: mouse strain-dependent alteration of glucose tolerance. FEBS Lett 1995;371:329-32.

51 Pedrazzini T, Cousin P, Aubert JF, Brunner HR. Transient inhibition of angiotensinogen production in transgenic mice bearing an antisense angiotensinogen gene. Kidney Int 1995;47:1638-46

52 Khillan JS, Li SW, Prockop DJ. Partial rescue of a lethal phenotype of fragile bones in transgenic mice with a chimeric antisense gene directed against a mutated collagen gene. Proc Natl Acad Sci USA 1994;91:6298-302. 53 Mullen RJ, LaVail MM. Inherited retinal dystrophy: primary defect in pig192:799-801. 54 Meindel A, Dry K, Herrman K, Manson F, Ciccodicola A, Edgar A, et al. A
gene (RPGR) with homology to the RCC1 guanine nucleotide exchange factor is mutated in X-linked retinitis pigmentosa (RP3). Nature Genet 1996;13:35-42.

55 Chang B, Bronson RT, Hawes NL, Roderick TH, Peng C, Hageman S, et al. Retinal degeneration in motor neuron degeneration:a mouse model of ceroid lipofuscinosis. Invest Ophthalmol Vis Sci 1994;35:1071-6.

56 Lindsay RM. Neurotrophic growth factors and neurodegenerative diseases: therapeutic potential of the neurotrophins and ciliary neurotrophic factor. Neurobiol Aging 1994;15:249-51.

57 Balan P, Davis-Poynter N, Bell S, Atkinson H, Browne H, Minson T. An analysis of the in vitro and in vivo phenotypes of mutants of herpes simplex type 1 lacking glycoproteins $\mathrm{gG}, \mathrm{gE}$, gL or the putative gJ. F Gen Virol 1994; 74:1245-8. 